\title{
Transient phantom limb pain following high thoracic erector spinae plane block in an amputee
}

\author{
Abdelghafour Elkoundi, MD (1) · Mehdi Samali, MD • Amine Meskine, MD • \\ Hicham Bakkali, PhD $\cdot$ Hicham Balkhi, PhD $\cdot$ Mustapha Bensghir, PhD
}

Received: 5 June 2020/Revised: 19 June 2020/Accepted: 19 June 2020/Published online: 10 July 2020

(C) Canadian Anesthesiologists' Society 2020

\section{To the Editor,}

Reactivation or induction of phantom limb pain following regional anesthesia (RA) is rarely encountered in clinical anesthesia practice. ${ }^{1,2}$ We describe a patient who experienced phantom limb pain after receiving an erector spinae plane (ESP) block. To our knowledge, no such event has been reported with this technique. Written informed consent was obtained from the patient for this report.

After sustaining an injury during a motor vehicle accident, a 42-yr-old man (American Society of Anesthesiologists physical status I) had a left aboveelbow amputation under general anesthesia. He had previously only reported surgical stump site pain in the immediate postoperative period that was well managed with oral analgesics (paracetamol and tramadol). There was no evidence of persistent upper-extremity phantom sensation or phantom pain. Three weeks after the amputation, he returned to the hospital for surgical revision of the stump site that had become infected. The procedure was performed under general anesthesia. To provide postoperative analgesia, we performed a preoperative ultrasound-guided ESP block at the T2 level with $20 \mathrm{~mL}$ of $0.25 \%$ bupivacaine.

The sensory block was assessed with pin-prick and cold tests, which showed that the block had developed in the upper extremity with a dermatomal coverage from the C5 to T3 level. Concomitantly, mild paresthesia was produced in the patient's "phantom" fingers.

\footnotetext{
A. Elkoundi, MD ( $₫) \cdot$ M. Samali, MD - A. Meskine, MD · H. Bakkali, PhD $\cdot$ H. Balkhi, PhD - M. Bensghir, PhD Department of Anesthesiology and Critical Care, Military Teaching Hospital Mohammed V, Faculty of Medicine and Pharmacy of Rabat, Mohammed V University, Rabat, Morocco e-mail: abd.el.koundi@gmail.com
}

Following the stump revision (during which he received $150 \mu \mathrm{g}$ fentanyl), the patient was monitored in the postanesthesia care unit. Thirty minutes later, the patient complained of excruciating arm pain. A new assessment showed complete sensory block of the upper extremity. Nevertheless, the patient reported a severe burning pain sensation in the anatomically absent left arm. He received a further $50 \mu \mathrm{g}$ fentanyl and a total of $8 \mathrm{mg}$ morphine with no change in the pain. Midazolam $2 \mathrm{mg} i v$ was given along with $60 \mathrm{mg}$ lidocaine $i v$, which reduced the phantom pain from 10 to $4(0=$ no pain; $10=$ worst possible pain $)$. After eight hours, after the sensory block dissipated, the patient complained of slight stump pain, which was managed with intravenous acetaminophen. The phantom pain also decreased gradually and resolved about one hour later. The patient made a good recovery and was discharged home without any further episodes of phantom pain.

Several reports have highlighted the reactivation or induction of phantom limb pain after RA yet its underlying mechanisms remain unclear. Even more puzzling is why it occurs infrequently and with such severe intensity. A proposed mechanism relates to a block-mediated decrease in the tonic inhibitory influence exerted by the brainstem reticular formation on dorsal horn neurons after complete loss of sensory input. ${ }^{3}$ The neurons fire spontaneously in high-frequency abnormal bursts. The resulting aberrant signalling through the spinothalamic tract may produce phantom limb pain. Paqueron et al. further suggested a block of the small-diameter fibres (A $\delta$ and $\mathrm{C}$-fibres) results in phantom pain. ${ }^{4}$

The phantom pain that occurred in this patient after a $\mathrm{T} 2$ ESP block intended for upper limb analgesia is supportive that a high thoracic ESP block might provide effective anesthesia of the upper limb; this is consistent with a recently published case report. ${ }^{5}$ Clinicians should be 
alerted to the risk of triggering the onset of phantom limb pain when performing RA procedures involving an already amputated limb.

\section{Disclosures None.}

Funding statement None.

Editorial responsibility This submission was handled by Dr. Hilary P. Grocott, Editor-in-Chief, Canadian Journal of Anesthesia.

\section{References}

1. Lee E, Donovan K. Reactivation of phantom limb pain after combined interscalene brachial plexus block and general anesthesia: successful treatment with intravenous lidocaine. Anesthesiology 1995; 82: 295-8.

2. Martin G, Grant SA, Macleod DB, Breslin DS, Brewer RP. Severe phantom leg pain in an amputee after lumbar plexus block. Reg Anesth Pain Med 2003; 28: 475-8.

3. Melzack R. Phantom limb pain: implications for treatment of pathologic pain. Anesthesiology 1971; 35: 409-19.

4. Paqueron X, Lauwick S, Le Guen M, Coriat P. An unusual case of painful phantom-limb sensations during regional anesthesia. Reg Anesth Pain Med 2004; 29: 168-71.

5. Ma W, Sun L, Ngai L, et al. Motor-sparing high-thoracic erector spinae plane block for proximal humerus surgery and total shoulder arthroplasty surgery: clinical evidence for differential peripheral nerve block? Can J Anesth 2019; 66: 1274-5.

Publisher's Note Springer Nature remains neutral with regard to jurisdictional claims in published maps and institutional affiliations. 